\title{
Research on the Influence Factors of Urban-Rural Income Disparity Based on the Data of Shandong Province
}

\author{
Sun Ye \\ Finance and economics college, Shandong Jiaotong University, Jinan, China \\ sunye1011@163.com
}

\begin{abstract}
This article has analyzed the influence factors of urban-rural income disparity in Shandong Province from two aspects: the development factors and the dual economy factors..The result indicates that along with the economy development in Shandong Province, urban-rural income disparity has the further expanded tendency. The influence of economic development factors is at the rising stage of Kuznets invert $U$ curve; Dual economy factors, population structure and policy deviation are the key factors which result in the enlargement of urban-rural income disparity.
\end{abstract}

Keywords: Urban-rural income disparity; Development factor; Dual economy factor; Principal components.

\section{INTRODUCTION}

Along with the fast development of national economy, urban-rural income disparity has also been gradually enlarging. Chinese Gini's coefficient in 2008 has reached as high as 0.47 . The problem of urban-rural income disparity has become the prominent issue which affects Chinese economy sustainable development and social stability. Shandong Province is at high level of economy development in China. In recent years, urban-rural income disparity has been expanding continuously: In 1989, urban-rural income disparity broke through 2 and it reached 2.91 in 2009. Although it was lower than the national average level 3.31 at the same time, it was at the high compared to the eastern coastal provinces. If considering the various kind of welfare, subsidy and preferential measure provided by government, the actual urban-rural income disparity was greater than this numeral by far. Speaking of Shandong Province, it has extremely vital practical significance to study urban-rural income disparity and the coordinate mechanism to adjust the development structure, realize urban and rural coordinated development, tap the potential ability of economy development, promote farmer to increase income and maintain regional stability.

\section{LITERATURE REVIEW}

Wherever Times is specified, Times Roman or Times Ne The expansion of urban-rural income disparity has aroused scholar's widespread interest. Lin Yifu (2003) thought that the improper developmental strategy of government was the main cause of income disparity. Ren Taizeng (2008) analyzed the reason from the angle of city deviation system which resulted in expanded income disparity. He thought the self-strengthened function of city deviation system could cause urban-rural income disparity to expand through accumulation, meanwhile could destroy its self-correct mechanism and suppress its reduction process. Chen Anping (2009) did empirical research and drew the conclusion that in the short term Chinese urban-rural income disparity is useful to promote economic growth in certain degree, but in the long term, if income disparity can't be suppressed, it will hinder the step of economy growth. He Jianfeng, Liu Jianping (2010) made dynamic econometrics analysis about urbanization, open policy and urban-rural income disparity based on VAR model and found urbanization and open policy are the main cause of income disparity. Han Qinghua, Xie Qiuyue (2010) proved that there existed long-term equilibrium relationship between urban-rural income disparity and economic growth in Shandong province through co-integration analysis and Granger test. This article will carry on empirical analysis to the influence factors of urban-rural income disparity in Shandong Province in order to provide decision basis for the related department to reduce the disparity. 
3. Empirical Analysis about URban - RuRal Income Disparity in Shandong Province

\subsection{Variables Choice}

\subsubsection{Dependent Variable Choice}

When we want to study the influence factors to urban-rural income disparity, dependent variable should be used to reflect urban rural disparity. Urban-rural income disparity can be measured by absolute target and relative target. Because absolute target usually has dimension to affect the analysis result, it is not adopted in the research. The commonly used relative targets are Gini's coefficient, Theil target and ratio of urban income to rural income. Mix urban-rural income disparity investigation data should be provided to compute Gini's coefficient. But in the past years, Chinese Statistics Department never carried on the mix urban-rural income investigation. It is unable to obtain real Gini's coefficient data. Theil target measures income disparity through entropy value number. It is used to judge the difference between integrated data and overall data. Ratio of urban and rural income equals to the disposable income of citizens divide by the pure income of countryside inhabitant. This target is easy to compute and direct-viewing. The data is accurate and feasible. Therefore this article chooses ratio of urban rural income to reflect urban-rural income disparity.

\subsubsection{Independent Variable Choice}

There are a lot of factors to result in urban-rural income disparity. These factors can be classified into two types: one is development factor and the other is dual economic factor. On the aspect of development factor, we choose economic growth rate, average GDP per person, fixed asset investment amount, foreign investment proportion, employment rate and so on to carry on the research. On the aspect of dual economic factor, we choose ratio of industrial structure of city and countryside, ratio of employment structure, ratio of population, relative price of industry and agriculture, comparison of urban and rural investment and so on. Among the above targets, some can reflect dual economic structure directly and some can reflect policy and mechanism indirectly. After comparison and screening, considering feasible principle to gain data, we finally choose 16 statistical targets which Table I arranged in order to take the model as the main reference target.

Table1. Statistic Targets To Influence Urban-Rural Income Disparity And Their Symbols

\begin{tabular}{|c|c|c|}
\hline Influence & Main target & symbol \\
\hline \multirow{9}{*}{ 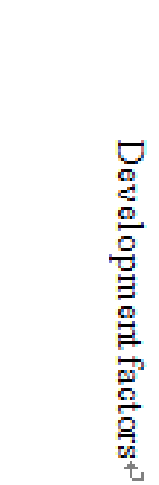 } & GDP & $\mathrm{X}_{1}$ \\
\hline & Average GDP per person & $\mathrm{X}_{2}$ \\
\hline & Fixed asset investment amount & $\mathrm{X}_{3}$ \\
\hline & Total income from financial & $\mathrm{X}_{4}$ \\
\hline & Ratio of industry a ddedvalue to GDP & $\mathrm{X}_{5}$ \\
\hline & Ratio of employment population in industry and & $\mathrm{X}_{6}$ \\
\hline & service department & $\mathrm{X}_{\mathrm{T}^{+}}$ \\
\hline & Unemploymentrate in urban city & $\mathrm{X}_{8}$ \\
\hline & Dependent degree of foreign trade & $\mathrm{X}_{9}+$ \\
\hline \multirow{6}{*}{ 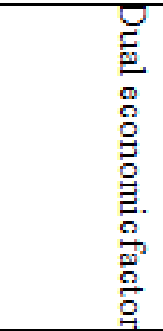 } & Proportion ofurbanpopulation to total population & $\mathrm{X} 10$ \\
\hline & Added value of industry to that of a griculture & $\mathrm{X} 11$ \\
\hline & Added value of to that ofindustry & $\mathrm{X} 12$ \\
\hline & Ratio of investment amount in city and countryside & $\mathrm{X} 13$ \\
\hline & Ratio of unstated investment to total investment & $\mathrm{X} 14$ \\
\hline & Relatedprice of industry and agriculture product & $\mathrm{X} 15$ \\
\hline
\end{tabular}

\subsection{Research Technique- Factor Analysis}

There are many targets which influence urban-rural income disparity, which can provide sufficient information for the research. But it will increase the complexity of analysis because of the relevance among the targets. Factor analysis method can solve this problem effectively. Its basic principal is to combine the original variables through analyzing internal structure of variable correlation coefficient 
matrix, explaining the information included in the multitudinous original variables with minority independent common factor variable, thus finding the primary factors which influence observation data, determining its weight objectively and avoiding subjective capriciousness. Suppose the number of samples is $\mathrm{n}$, each sample observes $\mathrm{p}$ variables, $\mathrm{Xij}$ is expressed the jth target data of the ith sample. Record $X_{i}=\left(X_{i 1}, X_{i 2}, \cdots, X_{i p}\right)^{T}$.The extraction public factors (also are called principal factors) are expressed by F1, F2,.., Fm ( $\mathrm{m}$ is the number of primarily factor, $\mathrm{m}<\mathrm{p}$ ). Factor analysis model may be described by the following model:

$\left\{\begin{array}{l}X_{1}=a_{11} F_{1}+a_{12} F_{2}+\cdots a_{1 m} F_{m}+\varepsilon_{1} \\ X_{2}=a_{21} F_{1}+a_{22} F_{2}+\cdots a_{2 m} F_{m}+\varepsilon_{2} \\ X_{p}=a_{p 1} F_{1}+a_{p 2} F_{2}+\cdots a_{p m} F_{m}+\varepsilon_{p}\end{array}\right.$

Its matrix formation is:

$X=A F+\varepsilon$

Where,

$$
A=\left(\begin{array}{ccc}
a_{11} & \cdots & a_{1 m} \\
\cdots & \cdots & \cdots \\
a_{p 1} & \cdots & a_{p m}
\end{array}\right)
$$

A is called component matrix. $\varepsilon_{\text {is }}$ called special factor matrix, $\varepsilon=\left(\varepsilon_{1}, \varepsilon_{2}, \cdots, \varepsilon_{n}\right)^{T}$. After establishing the factor model, each sample can be inspected in turn. Suppose the linear combination between $\mathrm{Fi}$ and $\mathrm{X}$ is:

$$
F_{i}=\beta_{i 1} X_{1}+\beta_{i 2} X_{2}+\cdots \beta_{i p} X_{p}(i=1,2 \cdots m)
$$

The equation (4) is called factor score function, $\beta=\left(\beta_{i 1}, \beta_{i 2} \cdots \beta_{i p}\right)^{T}$ is called factor score matrix, which can be estimated by regression analysis method. Finally, taking the following ratio $(\%$ of variance of principal factor $\mathrm{Fi} / \sum \%$ of variance of principal factor) as the weight, we can construct the synthesis score function of the sample:

$F=\delta_{1} F_{1}+\delta_{2} F_{2}+\cdots \delta_{m} F_{m}$

According to the synthesis score, we can compare and analyze the sample.

\subsection{Empirical research}

\subsubsection{Analysis of Development Factor}

We can get original data of development factor from 1996 to 2010 through Shandong Statistical Year book.

\begin{tabular}{|c|c|c|c|c|c|c|c|c|c|}
\hline Year & $\mathrm{z} 1 .$, & $\mathrm{X} 2$. & $\mathrm{x} 3 .$, & $\mathrm{X} 4$. & $\mathrm{X} 5$. & 86. & $\mathrm{X} 7.1$ & X8., & X9., \\
\hline 00. & 337 & 26.1 & 2543. & ו. & 35 & 6.9. & 3.2. & ו. 0.25 & .31 \\
\hline 2001. & 195. & 195. & 2808. & ו. 573 & 36 & 7.7 .1 & 3.1 & ו. 0.26 & 32 \\
\hline 2002. & 10276 & 1340. & 3509. & 610 & 36 & 49.9. & 3.6 .1 & ו. & 0.34 \\
\hline 2003.1 & 12078 & 13268 & 5328. & ו. 714 & 0.34 & 53.1. & 3.7 .1 & ו. & 0. \\
\hline 2004 & 15022 & 16413 & 7629 & 828 & 0.32 & 55.6. & 3.4 .1 & 0.33 & 0.43 \\
\hline 2005. & 18367 & 19934. & 10542 & 1073 & 0.02 & 30.0 .1 & 3.3.1 & 0 & 0.46 \\
\hline 2006. & 21900 & 23603. & 11136 & 1356 & 0.33 & 60.9 . & 3.3 .1 & ו. & 0.51 \\
\hline 2007.1 & 25777 & 27604 & 12537 & 1675 & 33 & 62.75 & 3.2 .1 & 0.36 & 0.51 \\
\hline 2008 & 30933 & 32935 & 15436 & 1957. & 0.33 & 62.6. & 3.5 .1 & 0.36 & 0.54 \\
\hline 2009. & 33897 & 35893. & 19031 & 2199 & 0.35 & 63.5. & 3.4 .1 & 0.28 & 0.56 \\
\hline 2010. & 39170 & 41106 & 23277 & 2749. & 0.37 & 64.5 .1 & 3.4 .1 & 0.33 & 0.55 \\
\hline
\end{tabular}

Table2. Original Data Of Development Factors

\section{Applicability Detection}

Table III lists KMO and Bartlett's test results. From it we can see $\mathrm{KMO}=0.564>0.5$, which satisfies the feasible standard of factor analysis. The significant value of Bartlett sphere examination is 
Sun Ye

$0.000<0.005$, therefore the hypothesis that the correlation coefficient matrix is unitary matrix is rejected. So the data are suitable for factor analysis.

Table3. KMO and Bartlett's Test

\begin{tabular}{|c|c|c|c|}
\hline \multirow{2}{*}{$\begin{array}{c}\text { Kaiser-Meyer-Olkin Measure of } \\
\text { Sampling Adequacy }\end{array}$} & Bpprox Chi-Square & df & sig. \\
\cline { 2 - 4 } & 223.271 & 36 & 0.000 \\
\hline 0.564 & &
\end{tabular}

Extraction of principal factor

There are many approaches to extract principal factor, such as maximum likelihood method, factor extraction method and so on. We selected the principal components analytic method in this study. The results calculated by SPSS17.0 are shown in table IV and table V.

Table4. Total Variance Explained

\begin{tabular}{|c|c|c|c|}
\hline \multirow[t]{2}{*}{ Component } & \multicolumn{3}{|c|}{ Initial Eigenvalues } \\
\hline & Total & $\%$ of Variance & Cumulative \% \\
\hline $\mathrm{X} 1$ & 6.172 & 68.575 & 68.575 \\
\hline $\mathrm{X} 2$ & 1.634 & 18.154 & 86.729 \\
\hline $\mathrm{X} 3$ & .971 & 10.793 & 97.522 \\
\hline $\mathrm{X} 4$ & .179 & 1.990 & 99.511 \\
\hline $\mathrm{X} 5$ & .027 & .302 & 99.813 \\
\hline X6 & .014 & .159 & 99.971 \\
\hline $\mathrm{X7}$ & .002 & .024 & 99.996 \\
\hline $\mathrm{X} 8$ & .000 & .004 & 100.000 \\
\hline $\mathrm{X9}$ & $2.716 \mathrm{E}-7$ & $3.018 \mathrm{E}-6$ & 100.000 \\
\hline
\end{tabular}

Extraction Method: Principal Component Analysis

\section{Establishing component matrix}

We established primitive component matrix of F11, F12, and found it was not easy to explain their connotation. (Because of article length limit, analysis result is left out). In order to make economic significance of the principle factors to be more obvious, we use varimax method to rotate and after 4 iterations, rotated component matrix is shown as table 4.

Calculation factor score and synthetic score

The component score coefficient matrix can be obtained using SPSS default regression analysis. The result is shown in table VI.

Table5. Rotated Component Matrix

\begin{tabular}{|c|c|c|}
\hline \multirow{2}{*}{ INDEX } & \multicolumn{2}{|c|}{ COMPONENT } \\
\cline { 2 - 3 } & $\mathbf{1}$ & $\mathbf{2}$ \\
\hline $\mathrm{X} 1$ & .978 & .199 \\
\hline $\mathrm{X} 2$ & .980 & .189 \\
\hline $\mathrm{X} 3$ & .972 & .202 \\
\hline $\mathrm{X} 4$ & .962 & .265 \\
\hline $\mathrm{X} 5$ & -.123 & .965 \\
\hline $\mathrm{X} 6$ & .979 & -.161 \\
\hline $\mathrm{X} 7$ & -.079 & .241 \\
\hline $\mathrm{X} 8$ & .685 & -.632 \\
\hline $\mathrm{X} 9$ & .984 & -.105 \\
\hline
\end{tabular}

Table6. Component Score Coefficient Matrix

\begin{tabular}{|c|c|c|}
\hline \multirow{2}{*}{ INDEX } & \multicolumn{2}{|c|}{ COMPONENT } \\
\cline { 2 - 3 } & $\mathbf{1}$ & $\mathbf{2}$ \\
\hline $\mathrm{X} 1$ & .158 & .123 \\
\hline $\mathrm{X} 2$ & .158 & .117 \\
\hline $\mathrm{X} 3$ & .157 & .126 \\
\hline $\mathrm{X} 4$ & .155 & .165 \\
\hline $\mathrm{X} 5$ & -.020 & .599 \\
\hline $\mathrm{X} 6$ & .158 & -.100 \\
\hline $\mathrm{X} 7$ & -.013 & .149 \\
\hline $\mathrm{X} 8$ & .111 & -.392 \\
\hline $\mathrm{X} 9$ & .159 & -.065 \\
\hline
\end{tabular}

According to the score matrix, we can calculate synthetic score of the two components by formula (4). 
Research on the Influence Factors of Urban-Rural Income Disparity Based on the Data of Shandong Province

Table7. Component Score of Development Factors

\begin{tabular}{|c|c|c|}
\hline Year & $\mathrm{F}_{11}$ & $\mathrm{~F}_{12}$ \\
\hline 2000 & -1.3439 & 0.34232 \\
\hline 2001 & -1.23832 & 0.66968 \\
\hline 2002 & -1.08214 & 1.00797 \\
\hline 2003 & -0.71085 & 0.08442 \\
\hline 2004 & -0.29061 & -1.34157 \\
\hline 2005 & 0.09245 & -1.23807 \\
\hline 2006 & 0.38253 & -0.97291 \\
\hline 2007 & 0.68743 & -0.85349 \\
\hline 2008 & 0.96426 & -0.23051 \\
\hline 2009 & 1.02581 & 0.99721 \\
\hline 2010 & 1.51334 & 1.53494 \\
\hline
\end{tabular}

\subsubsection{Analysis of dual economic factor}

According to the above analysis method of development factor, we can obtain the synthetic score of dual economic factor.

Table8. Component score of dual economic factors

\begin{tabular}{|c|c|c|}
\hline Year & $\mathbf{F}_{\mathbf{2 1}}$ & $\mathbf{F}_{\mathbf{2 2}}$ \\
\hline 2000 & -1.72322 & 1.47288 \\
\hline 2001 & -1.42122 & -0.57381 \\
\hline 2002 & -0.85376 & -0.50636 \\
\hline 2003 & -0.37456 & 0.0119 \\
\hline 2004 & -0.25282 & -1.06517 \\
\hline 2005 & 0.17538 & -0.34666 \\
\hline 2006 & 0.65675 & 0.18762 \\
\hline 2007 & 0.85558 & -0.23752 \\
\hline 2008 & 0.96522 & -1.28065 \\
\hline 2009 & 0.93105 & 0.29543 \\
\hline 2010 & 1.0416 & 2.04233 \\
\hline
\end{tabular}

Principal components regression analysis and result

Here we take $F_{11}, F_{12}, F_{21}, F_{22}$ as independent factor and ratio of urban income to rural income to make regression analysis. The regression equation is:

$Y=C+a_{1} F_{11}+a_{2} F_{12}+a_{3} F_{21}+a_{4} F_{22}+\xi$

Calculated by eviews6.0, the result is as the following:

Table9. Regression Analysis Result

\begin{tabular}{|c|c|c|c|c|}
\hline & Coefficient & Std. Error & t-Statistic & Prob. \\
\hline F1 & -0.014141 & 0.051066 & -0.276927 & 0.0011 \\
\hline F2 & 0.029235 & 0.012324 & 2.372107 & 0.0554 \\
\hline F3 & 0.180219 & 0.050807 & 3.547123 & 0.0121 \\
\hline F4 & -0.019961 & 0.013350 & -1.495211 & 0.0255 \\
\hline C & 2.718182 & 0.009488 & 286.4962 & 0.0000 \\
\hline R-squared & 0.978503 & \multicolumn{2}{|c|}{ Mean dependent var } & 2.718182 \\
\hline Adjusted R-squared & 0.964171 & \multicolumn{2}{|c|}{ S.D. dependent var } & 0.166242 \\
\hline S.E. of regression & 0.031467 & \multicolumn{2}{|c|}{ Akaike info criterion } & -3.776797 \\
\hline Sum squared resid & 0.005941 & \multicolumn{2}{|c|}{ Schwarz criterion } & -3.595935 \\
\hline Log likelihood & 25.77238 & \multicolumn{2}{|c|}{ Hannan-Quinn criter. } & -3.890804 \\
\hline F-statistic & 68.27645 & \multicolumn{2}{|c|}{ Durbin-Watson stat } & 1.902112 \\
\hline Prob(F-statistic) & 0.000039 & \multicolumn{3}{|l}{} \\
\hline
\end{tabular}

The regression equation is

$Y=2.72-0.014 * F_{11}+0.029 * F_{12}+0.18 * F_{21}-0.02 F_{22}+\xi$ 
In order to study the effect of each variable to urban-rural income disparity, we express the principal factors with each variable and get the following equation:

$$
\begin{aligned}
& Y=2.72+0.0011 \mathrm{x}_{1}+0.0013 \mathrm{x}_{2}+0.0012 \mathrm{x}_{3}+0.0005 \mathrm{x}_{4} \\
& +0.0223 \mathrm{x}_{5}-0.0092 \mathrm{x}_{6}+0.0070 \mathrm{x}_{7}-0.0183 \mathrm{x}_{8}+0.0081 \mathrm{x}_{9} \\
& +0.0741 \mathrm{x}_{10}+0.0774 \mathrm{x}_{11}+0.0695 \mathrm{x}_{12}+0.0790 \mathrm{x}_{13} \\
& +0.0700 \mathrm{x}_{14}+0.0533 \mathrm{x}_{15}+0.0508 \mathrm{x}_{16}
\end{aligned}
$$

\section{ConClusion}

The model demonstrates that economic development has promoted the enlargement of urban -rural income disparity, which conforms to the general rule of inverse $U$ curve most scholars agreed. That is in the preliminary stage of economic development, economic growth will increase urban-rural income disparity. When economy develops to some certain degree, it can reduce income disparity. This result has also shown that since reform and open policy, urban - rural income disparity has expanded with the fast development in Shandong Province. In the short period, economic development still has the possibility to cause urban-rural income disparity to continue to expand. In the dual economic factor, the ratio of added value in non-agricultural production to agricultural production reflects the dual economical characteristic, the bigger the ratio is, the greater the disparity between urban and rural income is. The ratio of urban investment to rural investment can reflect city policy deviation from certain degree and it will result in the lag development of rural economy which enlarges the urban-rural income disparity. The regression coefficient of urban to rural population is positive, which shows that urbanization has intensified the urban-rural income disparity.

\section{ACKNOWLEDGMENT}

This work was supported by Statistical Key Topics fund in Shandong Province (KT13033).

\section{REFERENCES}

[1] Lin Yifu, Liu Miingxing. Growth convergence and income allocation[J]. World economy. 2003,8(26):3-14.

[2] Ren Taizeng. Urban bias system and its effect to urban-rural income disparity[J]. Jiangxi social science. 2008.5:72-77.

[3] Chen Anping. Research on the relationship between urban-rural income disparity and economic development [J]. Journal of the central finance and economics university, 2009(6):54-58.

[4] He Jianfeng, Liu Jianping. Urbanization, open policy and urban-rural income disparity: empirical analysis based on VAR model[J]. Research of technical economy and management. $2010.4: 16-19$.

[5] Han Qinghua, Xie Qiuyue. Study on the relationship between urban-rural income disparity and economic development empirical study based on the data from 1980 to 2007[J]. Journal of Shandong financial college. $2010.5: 71-73$.

\section{AUTHOR'S BIOGRAPHY}



Sun Ye (1969), female, professor of institute of finance and economics in Shandong Jiaotong University. Main research field: microeconomics, macroeconomics, regional economics. 